\title{
Article
}

\section{Partnered Research Experiences for Junior Faculty at Minority-Serving Institutions Enhance Professional Success}

\author{
Andrew G. Campbell, ${ }^{* \dagger}$ Michael J. Leibowitz, ${ }^{*}$ Sandra A. Murray, ${ }^{* \|}$ \\ David Burgess, ${ }^{* \mathbb{l}}$ Wilfred F. Denetclaw, ${ }^{* \#}$ Franklin A. Carrero-Martinez, ${ }^{* @ * *}$ \\ and David J. Asai ${ }^{*+\dagger}$
}

${ }^{\dagger}$ Department of Molecular Microbiology \& Immunology and ‡Brown University Initiative to Maximize Student Development Program, Brown University, Providence, RI 02912; § Department of Medical Microbiology and Immunology, University of California-Davis, Davis, CA 95616; "Department of Cell Biology and Physiology, School of Medicine., University of Pittsburgh, Pittsburgh, PA 15261; IIDepartment of Biology, Boston College, Chestnut Hill, MA 02467; " Department of Biology, San Francisco State University, San Francisco, CA 94132; ${ }^{\circledR}$ Department of Biology, University of Puerto Rico, Mayagüez, Mayagüez, PR 00681; ${ }^{+\dagger}$ Science Education, Howard Hughes Medical Institute, Chevy Chase, MD 20815

Submitted February 14, 2013; Revised May 23, 2013; Accepted May 24, 2013

Monitoring Editor: Jeff Schinske

\begin{abstract}
Scientific workforce diversity is critical to ensuring the realization of our national research goals and minority-serving institutions play a vital role in preparing undergraduate students for science careers. This paper summarizes the outcomes of supporting career training and research practices by faculty from teaching-intensive, minority-serving institutions. Support of these faculty members is predicted to lead to: 1) increases in the numbers of refereed publications, 2) increases in federal grant funding, and 3) a positive impact on professional activities and curricular practices at their home institutions that support student training. The results presented show increased productivity is evident as early as $1 \mathrm{yr}$ following completion of the program, with participants being more independently productive than their matched peers in key areas that serve as measures of academic success. These outcomes are consistent with the goals of the Visiting Professorship Program to enhance scientific practices impacting undergraduate student training. Furthermore, the outcomes demonstrate the benefits of training support for research activities at minority-serving institutions that can lead to increased engagement of students from diverse backgrounds. The practices and results presented demonstrate a successful generalizable approach for stimulating junior faculty development and can serve as a basis for long-term faculty career development strategies that support scientific workforce diversity.
\end{abstract}

\section{INTRODUCTION}

Race, ethnic status, and underprivileged backgrounds shape social identities, which in turn influence educational perfor-

DOI: $10.1187 /$ cbe.13-02-0025

Address correspondence to: Andrew G. Campbell (Andrew _Campbell@Brown.edu).

*American Society for Cell Biology Minorities Affairs Committee. ${ }^{*}$ Currently an AAAS Revelle Fellow in Global Stewardship.

The views and conclusions presented in this article are the authors' alone and do not necessarily reflect the views of the U.S. government.

(C) 2013 A. G. Campbell et al. CBE-Life Sciences Education (C) 2013 The American Society for Cell Biology. This article is distributed by The American Society for Cell Biology under license from the author(s). It is available to the public under an Attribution- mance and academic success (Steele, 1997; Spencer et al., 1999; National Academy of Sciences [NAS], 2011). The low numbers of individuals from these backgrounds, especially racial and ethnic minorities, who pursue careers in science, technology, engineering, and mathematics (STEM) is often cited as one of the factors likely to impede the United States' future scientific progress (NAS, 2011). While the pool of prospective scientists among these backgrounds continues to grow, few end up pursuing science careers (Summers and Hrabowski,

Noncommercial-Share Alike 3.0 Unported Creative Commons License (http:/ / creativecommons.org/licenses / by-nc-sa/3.0).

"ASCB ${ }^{\circledR}$ " and "The American Society for Cell Biology ${ }^{\mathbb{Q}) " ~ a r e ~ r e g i s-~}$ tered trademarks of The American Society for Cell Biology. 
2006), suggesting that barriers to opportunities and participation continue to limit success.

Minority-serving institutions (MSIs), which include historically black colleges and universities (HBCUs), Hispanicserving institutions (HSIs), and tribal colleges and universities (TCUs), are defined by enrollments of $25 \%$ or more underrepresented minority (URM) students (U.S. Department of Education, 2008). As of 2004, 58, 63.3, 52.9, and 38.6\%, respectively, of black, Hispanic, Asian, and Native American students attended MSIs, placing these institutions at the forefront of educating and training of U.S. racial and ethnic minorities (U.S. Department of Education, 2008). The overall fraction of U.S. minority students at MSIs has also increased from $13.5 \%$ in 1984 to 32\% in 2004 (U.S. Department of Education, 2008).

Faculty members at MSIs have greater and more regular access to URM students, making them important participants in the national effort to address the issue of underrepresentation in STEM careers. Because the impact of the MSIs is exceptional, strengthening the professional development of faculty is critical for the development of URM students. For example, HBCUs award $50 \%$ of the degrees in mathematics and $40 \%$ of the degrees in physics held by African Americans (Gasman, 2008, 2009; Burrelli and Rapoport, 2008). Moreover, although only five of the top 50 producers of African-American baccalaureates who go on to science and engineering $\mathrm{PhDs}$ are HBCUs, these five account for $25 \%$ of future black PhDs (Gasman, 2008, 2009; Burrelli and Rapoport 2008). Trainees from minority communities who pursue careers in the healthcare fields go on to serve as care providers in minority communities (Murray-García et al., 2001; Komaromy et al., 1996). Similarly, a larger percentage of black faculty members who hold science, engineering, and health doctorates-many who often began their own careers in minority communities-often pursue careers in the scientific fields at MSIs and in minority communities (National Science Foundation [NSF], 2011). As a result, they are directly involved in addressing the problems and challenges faced by their communities while contributing to the education and diversification of our national workforce.

The Minorities Affairs Committee (MAC; www.ascb.org) is a standing committee of the American Society for Cell Biology (ASCB) that began its work in 1980. Its membership includes faculty from diverse ethnicities and scientific backgrounds and from both MSI and non-MSI teaching-intensive and research-intensive institutions. Past and current committee members are also prominent scientists, educators, mentors, and role models. In addition to supporting the mission and programs of ASCB, MAC's unique mission is to increase diversity in cell biology and address issues affecting underrepresented racial and ethnic minorities in the sciences. This is achieved by supporting educational training and the participation of minorities at all leadership levels in the society, and by working to improve the professional development of faculty members, especially those at MSIs. This is being achieved through programs such as the Linkage Fellows Program, the Junior Faculty and Postdoctoral Fellows Career Development Workshop, and the Visiting Professorship (VP) Program.

Faculty members establish the conceptual frameworks in which students learn. The development of students who are both reflective and inquisitive in the classroom is dependent on access to educators who are themselves also reflective and inquisitive and who possess a good understanding of the practice of science inquiry (Minstrell and van Zee, 2000; Drayton and Falk, 2006). Further, the growing appreciation for the impact of inquiry-based learning, including researchbased laboratory courses (Garde-Hansen and Calvert, 2007; President's Council of Advisors on Science and Technology, 2012), means that faculty research training and experience will become an increasingly important prerequisite for effective biology education (Feldman, 1987). In response to these needs, the VP Program was designed in part to provide research opportunities to faculty members who spend the majority of their time in the classroom, to enable them to become better able to improve curricular science content and pedagogy.

The MAC developed the VP Program to meet the professional scientific needs of faculty members at MSIs by providing research training to enhance scholarly practices with the goal of strengthening educational and research activities at their home institutions. In assessing the effectiveness of the VP Program, we asked the following questions: 1) Does the program enhance MSI faculty scholarly practices? 2) Does the program impact the teaching practices of the faculty participants? The present paper reports on the outcomes for 32 Visiting Professors and compares their progress with that of 129 matched MSI faculty peers.

\section{METHODS}

\section{The VP Training Program}

The VP Program was established in 1997 with the support of a Minority Access to Research Careers grant from the National Institute of General Medical Sciences. The program helps to strengthen research infrastructure and teaching practices at MSIs where large numbers of underrepresented racial and ethnic minority students receive their undergraduate degrees and research training. It also provides faculty members with professional development opportunities not readily available at their home institutions by enabling them to engage in research activities that increase their ability to publish scientific works, present their findings at regional and national scientific meetings, and develop extramurally funded research programs. The program also supports the professional development and enhances the career trajectories of the participants by supporting teaching and curricular practices and by encouraging the faculty members to expand their professional networks. Participants receive 8- to 10-wk training internships in the laboratories of host scientists at researchintensive institutions. Faculty sponsors are often ASCB members, and all maintain active research programs. These faculty sponsors are accomplished scholars who have both laboratory and classroom training expertise. Their research interests also align well with the goal of the program and mission of MAC and the ASCB. In any year, a faculty sponsor may host only one VP Program participant. Sponsoring faculty and Visiting Professors are not required to be members of ASCB to participate in the VP Program.

\section{Selection of VP Program Participants}

Calls for applications and nominations to the VP Program are made to faculty at research-intensive institutions and 
MSIs. Application calls are also made through published notices distributed at scientific meetings, the ASCB website and newsletter, email announcements, and advertisements in specialized scientific journals. Applicants are drawn from a national pool, and applications are reviewed by the MAC VP selection committee comprising several members of the MAC. Participants selected for the program are those who hold academic appointments at MSIs, especially teaching institutions, throughout the United States and its territories. Of the 32 program participants described in this paper, there are 19 African Americans, four Asians, three Caucasians, and six Hispanics. Nineteen are female. At the time of their participation in the program, all were employed as full-time regular faculty with academic duties that included classroom teaching of undergraduate students. Visiting Professors carried out cell biology-based laboratory research with faculty mentors in the summers, during which time they received a stipend and a modest allowance to support the research activities.

All VP applicants are required to outline a research plan as well as the nonmaterial support and mentoring they will receive from sponsors. The successful outcome of this plan is expected to be the launching of independent research programs by the Visiting Professors, which will allow them to engage students at their home institutions in the classroom and in teaching and research labs. Consideration is given to both short-term and long-term goals and objectives of the applicants, their skill sets, and the value of the scientific outcomes of the work to be completed. Consideration is also given to the infrastructures and capacities at the applicants' home institutions, because those resources may not be equivalent to those at the sponsors' institutions. In particular, consideration of the feasibility of continuing some aspect of the work at the Visiting Professor's home institution is evaluated, including limitations related to instrument availability and experimental model system costs and availability. Faculty members may participate in the VP Program more than once, but participation thus far has been limited to a maximum of two summer training experiences, with preference given to junior untenured scientists in tenure-track positions or en route to tenure-track positions.

\section{Assessment of Participants and Program Outcomes}

From 1997 to 2012, 43 unique VP Program participants completed $60 \mathrm{VP}$ experiences (Figure 1). The present evaluation is limited to participants who were at least 1 yr beyond their first VP experience. This represents a group of 32 unique scientists participating in $49 \mathrm{VP}$ experiences, with 17 of 32 participating in the program twice through 2011. Because the number of applicants to the program who were awarded but declined VP support is small, it was not possible to use this group for accurate comparisons with program participants. Accordingly, matched faculty peers at the same academic ranks and at the same home institutions and in the same departments as VP Program participants were selected as the control group. The period 5 yr prior to participation in the VP Program and the period after participation were compared for publications and grants authored by Visiting Professors and by a group of 129 matched MSI faculty peers.

Self-reported and public online data were collected for the VP Program participants during the period 19972011. Database searches were performed using PubMed
VP Program participants

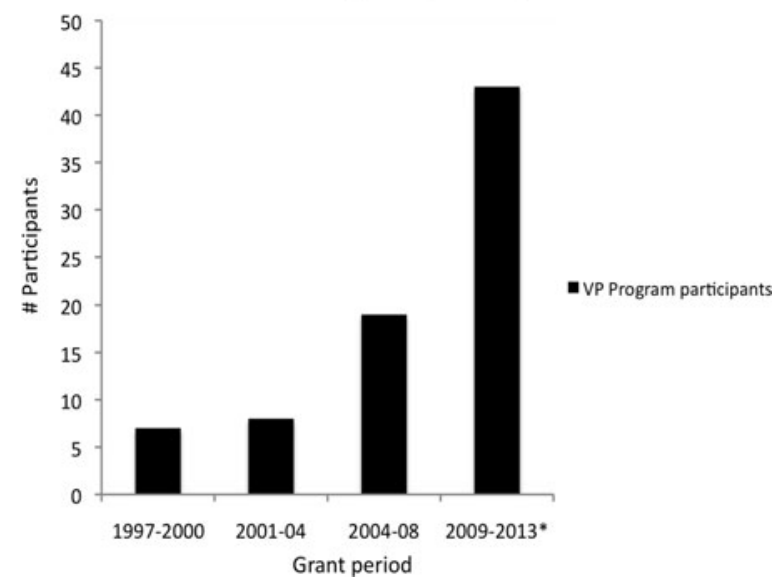

Figure 1. Faculty participants in the VP Program. The total number of VP Program participants during each grant-funding period of the program is shown. Thirty-two unique faculty members participated in the program through 2011. Seventeen of these participants completed a second-year VP experience, yielding a total of 49 reported VP experiences. *, For the grant period 2009-2013, participant numbers are given only for 2009-2011.

(www.ncbi.nlm.nih.gov/pubmed?db=pubmed) to access publications from MEDLINE available through 2012. Information on federal grant funding was collected from publicly accessible databases, including the National Institutes of Health (NIH) RePORTER database (http: / / projectreporter .nih.gov/reporter.cfm), the NSF Award Search database (www.nsf.gov/awardsearch) and the U.S. Department of Agriculture (USDA) National Institute of Food and Agriculture (NIFA) database (http://cris.csrees.usda.gov/ menu.html). For funding analysis, unique grants held by Visiting Professors and controls, as either principal investigator or co-principal investigator, were included. A similar comparison was performed after Visiting Professors completed their training and includes analyses of funding data available through 2012. The number of peer-reviewed publications in the 5 yr prior to their participation in the VP Program was compared with publications during the same period of their matched MSI faculty peers. Similar comparative analyses of publications "post-VP training" were also carried out. The 5 -yr period of funding analysis and publication analysis that precedes the VP training experience of each VP Program participant is referred to as the "pre-VP era." The period after which participants have completed their VP training is referred to as the "post-VP era." This period has been as short as 2 yr for participants who completed their VP training in 2009, and as long as 14 yr for participants completing training in the 1997-2000 period. Grants awarded to matched MSI faculty peers or to participants in the year that an individual began the VP Program were assigned to the pre-VP era. Similarly, manuscripts published in the year that faculty members became participants of the VP Program were assigned to the pre-VP era.

Data on curricular and other ancillary activities reported here represent participant self-reported data. They were collected through confidential online surveys and interviews at the conclusion of training that provided Visiting Professors 
the opportunity discuss experiences, work products, future research, and teaching plans and to provide feedback on the strengths and weaknesses of the program.

\section{Overview of Data Analysis and Statistical Method}

Collected data were used to evaluate accomplishments of program participants in areas that define professional success and tendency toward success in the sciences. The evaluation criteria include a measure of the average numbers of publications and average numbers and sizes of federal grants. Other posttraining activities, including curricular activities, are also reported, because these also serve as measures of the impact of VP Program training on faculty professional development and activities that impact student training and learning.

Mixed-effects regression modeling was used to evaluate whether the number of publications, number of funded grants, and grant-funding amounts following the VP experience differed for Visiting Professors compared with their MSI-matched, near-peer colleagues. The parameter estimates of interest were the fixed-effect estimate for being a Visiting Professor. Each model was adjusted for the measurement in the 5-yr period prior to program enrollment (fixed effect), and individuals were nested within institutions (random effect). The number of publications and grants were assumed to follow a Poisson distribution, and the total grant amounts were assumed to be normally distributed after $\log (x+1)$ transformation.

The period of data analysis following VP training for Visiting Professors and their matched peers were identical. This period was as short as $2 \mathrm{yr}$ for participants of the program in 2009-2010 and 2010-2011 in the 2009-2013 cohort and as long as $14 \mathrm{yr}$ for the $1997-2000$ cohort.

\section{RESULTS}

\section{Characteristics of Program Participants as a Function of Time}

Since the VP Program's inception in 1997, the number of participants has grown steadily. With the exception of one minority faculty participant from a majority-serving, researchintensive institution, all participants came from MSIs. For the 1997-2000 period, six trainees participated in the program, which compares with 32 participants for the 2009-2011 period. Although the participation data for the 2009-2013 period are incomplete, the number of participants through 2011 was twice that of the prior 4-yr period. Because the number of applicants to the program has always outpaced available slots (unpublished data), individuals invited to participate in the program are selected through a competitive process.

None of the participants in the program to date has reported on his or her disability status, and therefore only data on racial and ethnic status are available (Figure 2). African Americans and Hispanics account for the majority of participants and applicants to the program (unpublished data). While there has been a steady increase in applications and participants from HBCUs, there has been a less consistent rise in the number of applications from faculty members at HSIs. Asian Americans accounted for a small fraction of applicants to the program and were only represented in the program in the 2001-2004 and 2009-2013 periods. Although one Native American faculty scientist served as a co-mentor and

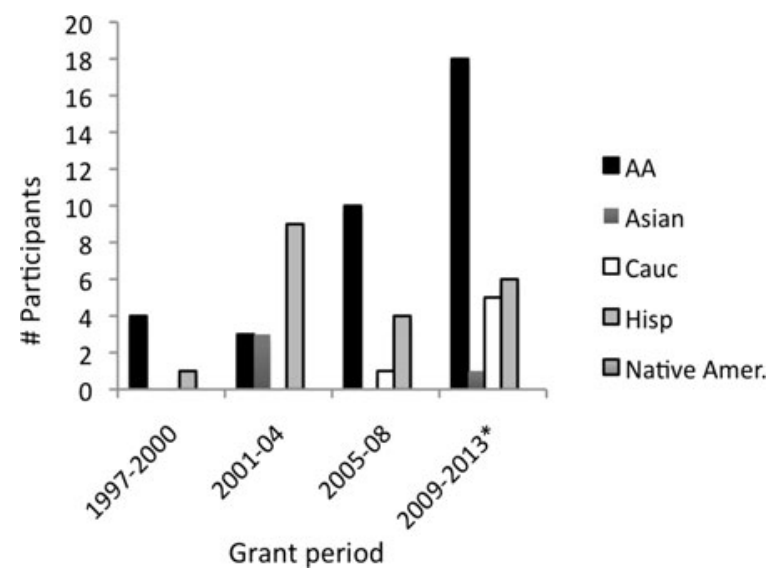

Figure 2. Racial and ethnic breakdown of participants of the VP Program. Participants are presented according to the funding periods they were involved in the program and over the life of the program. Faculty members participating in the program more than once are also included. *, For the grant period 2009-2013, participant numbers are given only for 2009-2011.

co-host, no Native American faculty members have participated in the program as a sponsor or as a Visiting Professor. The VP Program supports faculty at MSIs regardless of race and ethnic background, and there has been steady increase in the number of participating non-URM faculty members in the program in the last 5-7 yr. From 2009 to 2011, non-URM faculty members accounted for $17 \%$ of all participants. This compares with $7 \%$ for the $2005-2008$ period and $0 \%$ for both the 1997-2000 and the 2001-2004 periods. Women have been well represented in the VP Program, accounting for $60 \%$ of all participants. For each 4 -yr period of analysis, female participants outnumbered males.

\section{Participant Publications}

The 32 program participants reported publishing 91 manuscripts or book chapters and cite 39 of their published manuscripts as coming after their VP training experiences. The majority of these publications were generated within 3$5 \mathrm{yr}$ of completing their training. A number of the publications self-reported by VP Program participants, however, included publications with postdoctoral advisors and have attribution to their postdoctoral training institutions. Although useful in measuring productivity, these works do not accurately reflect the independent career achievements of participants or the impact of the VP Program, because they are not all related to VP training experiences. For more accurate assessment of the impact of VP training on participant achievements, refereed publications generated during the pre-VP and post-VP eras by participants while in their current positions were retrieved from PubMed and compared with publication output by matched MSI faculty peers. These data are summarized in Table 1. In the pre-VP era, the average manuscript output per Visiting Professor was the same as the output for the MSI faculty peer controls $(0.84$ and 0.85$)$. In contrast, during the post-VP era, the average number of manuscripts produced per participant increased to 1.37 , versus 0.82 for the matched MSI faculty peers $(p=0.004)$. The change in SD (or $\sigma)$ values for publications by Visiting Professors in the pre-VP era (1.90) 
Table 1. Comparison of average number of publications and research grants per Visiting Professor versus matched MSI faculty peers $^{\mathrm{a}}$

\begin{tabular}{|c|c|c|}
\hline \multicolumn{3}{|c|}{ Publication record ${ }^{b}$} \\
\hline Period & $\begin{array}{l}\text { Average number of } \\
\text { publications per } \\
\text { matched MSI peer } \\
\quad(n=129)\end{array}$ & $\begin{array}{c}\text { Average number of } \\
\text { publications per VP } \\
\text { Program participant } \\
\qquad(n=32)\end{array}$ \\
\hline Pre-VP & 0.85 & 0.84 \\
\hline Post-VP & 0.82 & 1.37 \\
\hline
\end{tabular}

\begin{tabular}{lcc}
\hline \multicolumn{2}{c}{ Federal grant support $^{\mathrm{c}}$} \\
\hline Period & $\begin{array}{c}\text { Average number of } \\
\text { new grants per } \\
\text { matched MSI } \\
\text { peer }(n=129)\end{array}$ & $\begin{array}{c}\text { Average number of new } \\
\text { grants per VP } \\
\text { Program participant } \\
(n=32)\end{array}$ \\
\hline Pre-VP & 0.3 & 0.06 \\
Post-VP & 0.16 & 0.59 \\
\hline
\end{tabular}

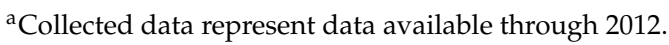

${ }^{b}$ Publications. PubMed was used to access science journal publications from MEDLINE. Publications $5 \mathrm{yr}$ prior to participation in the VP Program and only for faculty members at their current institution vs. post-VP publications were compared $(95 \%$ CI 1.18-2.44, $p=$ $0.004)$. The $\mathrm{SD}$ (or $\sigma$ ) for publications by matched peers in the pre-VP era and post-VP era were 1.84 and 2.10 , respectively. For publications by Visiting Professors in the pre-VP era and post-VP era, these values were 1.9 and 2.37 , respectively.

${ }^{\mathrm{C}}$ Research grants: Using NIH, NSF, and USDA funding databases, federal grants held $5 \mathrm{yr}$ prior to faculty participation in the VP Program vs. post-VP successes were compared (95\% CI 2.22-8.98, $p<$ 0.001). Comparisons were made between Visiting Professors who were matched against their peers in the same department in the same home institution. Research grant funding directly and indirectly related to work completed by Visiting Professors. Grants identified were new grants to faculty and are grants on which faculty members serve either as principal investigators or co-principal investigators. The SDs for the number of new grants secured by matched peers in the pre-VP era and post-VP era were 0.78 and 0.41 , respectively. For Visiting Professors in the pre-VP era and post-VP era, these values are calculated to 0.24 and 1.38 , respectively.

versus the post-VP era (2.37) is small. Similarly the change in SD for publications by the matched MSI peers is also observed to be small, going from 1.84 in the pre-VP era to 2.10 in the post-VP era. Figure 3 shows the distribution of post-VP training publications of program participants over time. Approximately half of all publications attributed to VP Program participants were produced by participants who completed their training from 1997-2000. The 2001-2004 support period represents the period in which the lowest publication output by Visiting Professors is reported (Figure 3). This also aligns with the lowest level of publication output by Visiting Professors in the pre-VP era and the lowest number of new grants secured by Visiting Professors in the post-VP era. Although not a favorable outcome, this observation is consistent with decreasing numbers of articles produced by U.S. scientists per federal grant beginning in 2001 (Boyack and Jordan, 2011). It also coincides with the start of decline in NIH grant success rates for both Research Projects Grants (RPGs) and R01 Equivalent Awards (R01s). These values decreased from 32.1\% for
Publication numbers and periods

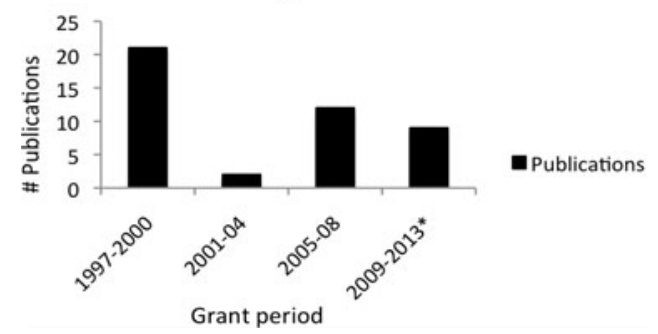

Figure 3. Publications by Visiting Professors. The years given correspond to the training period. Publications reported are limited to refereed publications retrieved from PubMed that list the participant's institution at the time of training. *, For the grant period 2009-2013, participant numbers are given only for 2009-2011.

RPGs and $31.7 \%$ for R01s in 2001 to $25 \%$ and $24.6 \%$ in 2004 , respectively, representing the largest-ever drop and rate of decrease in federal grant funding (Federation of American Societies for Experimental Biology, 2013). It was not possible to establish causal relationships between funding and publications. Overall, VP research training correlates positively with posttraining publications, and individuals who participated in the program more than once produced $80 \%$ of their manuscripts in journals of equal or higher impact factors as those of their MSI peers (unpublished data).

\section{Grant Funding}

The pairing of VP Program participant and host scientist is based on common research interests and expertise, and these pairings have resulted in research collaborations. More than one-third of participants report that they collaborate with or are in the process of establishing collaborations with their host sponsors, which will help to sustain the momentum of work initiated during the VP training experience. As part of these collaborations, some participants report jointly submitting grant applications with their past sponsors.

Many VP Program participants attribute securing grants that support their research and teaching practices to their VP training. Of the past 32 Visiting Professors, 13 reported grant funding for work directly related to their VP training experience. Of this group, 10 reported having received grants for work on which they serve as principal investigator or as co-principal investigator. These include federal research grant awards, professional development grants, and teaching grants. An additional three participants reported receiving grant funding in the form of state or private grants; only two of the past 32 participants reported that they did not apply for grant funding following the VP training experience. The success in securing federal grants by Visiting Professors, which is an indicator of funding success and is concordant with the federal funding mechanism used to support the VP Program, was examined (Table 1). Grant support correlated positively with VP training, and participants attribute securing grants supporting their research and teaching practices to their VP training. Forty percent of past Visiting Professors credit funding for grants on which they serve as principal or co-principal investigators to their VP training experiences. Together, the 32 faculty members who would eventually 
Table 2. Comparison of average size of research grants (in 1000s of US dollars) per Visiting Professor versus faculty peers ${ }^{\mathrm{a}}$

\begin{tabular}{lcc}
\hline & \multicolumn{2}{c}{ Size of grant support } \\
\cline { 2 - 3 } Period & $\begin{array}{c}\text { Average grant size } \\
\text { per matched MSI } \\
\text { peer }\end{array}$ & $\begin{array}{c}\text { Average grant size } \\
\text { per VP Program } \\
\text { participant }\end{array}$ \\
\hline Pre-VP & 202 & 17.53 \\
Post-VP & 124 & 117.18 \\
\hline a Using NIH, NSF, and USDA funding databases, grants held 5 yr \\
prior to faculty participation in the VP Program vs. post-VP suc- \\
cesses were compared. Comparisons were made between Visiting \\
$\begin{array}{l}\text { Professors who were matched against their peers in the same de- } \\
\text { partment in the same home institution. In total, 32 Visiting Profes- } \\
\text { sors were compared with 129 peer faculty. Research grant funding } \\
\text { directly and indirectly related to work completed by Visiting Profes- } \\
\text { sors. Grants identified were only new grants by faculty since complet- } \\
\text { ing the VP Program and represent grants on which participants were } \\
\text { either principal investigators or co-principal investigators. Collected } \\
\text { data include only data available through 2012. }\end{array}$ \\
\hline
\end{tabular}

become Visiting Professors held two federal grants (NIH, NSF, NIFA) in the pre-VP era (average of 0.06 grants per person); their number of grants increased nearly 10-fold to a total of 19 in the post-VP era (average of 0.59 grants per person). In comparison, the 129 MSI faculty peers comprising the control group held 39 federal grants ( 0.30 grants per person) in the pre-VP era, and decreased to a total of 19 grants in the post-VP era (average of 0.15 grants per person).

The average amount of federal grant dollars available per Visiting Professor in the pre-VP era totaled $\sim \$ 17,530$ compared with $\sim \$ 117,180$ in the post-VP era (Table 2). For the matched peers, the post-VP-era new grant total was $\$ 124,000$ compared with $\$ 202,000$ in the pre-VP era. The smaller average size of MSI grants, compared with what is reported for principal investigators at research-intensive institutions (NIH, 2012b), is consistent with the smaller scale of the research programs and different mission at MSIs.

\section{Posttraining Activities Related to Student and Professional Development}

VP Program participants reported on a number of other activities and outcomes that have been influenced by their training experiences, and these are summarized in Table 3. Research training has influenced teaching practices by program participants, as 22 of the past 32 participants reported developing new courses or instituting curricular changes that integrate content from their VP experiences. Curricular improvements reported include introduction of cutting-edge methodologies such as polymerase chain reaction technology into courses, establishing independent research projects as components of courses, and use of journal articles and research proposal writing exercises. Other curricular upgrades and revisions included addition of online components to teaching practices.

As indicated in Table 3, 31 of 32 VP Program participants report that they mentor undergraduate students. Nineteen report that they have sent one or more of their students on to graduate school. Half of all participants report that they have assumed leadership roles at their home institutions and
Table 3. Ancillary activities of Visiting Professors following training ${ }^{\mathrm{a}}$

\begin{tabular}{lc}
\hline \multicolumn{2}{c}{ Posttraining activities } \\
\hline \multicolumn{1}{c}{ Activity } & $\begin{array}{c}\text { Number of participants } \\
\text { (32 total) }\end{array}$ \\
\hline $\begin{array}{l}\text { Research collaborations with host } \\
\text { scientist }\end{array}$ & 22 \\
New course development or \\
curricular improvements \\
$\begin{array}{l}\text { Student research training and } \\
\text { mentoring }\end{array}$ \\
$\begin{array}{l}\text { New leadership roles } \\
\text { Attendance at professional } \\
\text { scientific meeting }\end{array}$ \\
$\begin{array}{l}\text { Professional society membership } \\
\text { aparticipants of the VP Program reported on activities at their home }\end{array}$ \\
$\begin{array}{l}\text { institutions and in the larger scientific community related to training } \\
\text { and professional development upon the completion of the program. }\end{array}$ \\
$\begin{array}{l}\text { Thirty-two participants were queried. Activities engaged in are listed } \\
\text { here and the number of participants engaging in each activity is } \\
\text { presented. }\end{array}$
\end{tabular}

in the larger scientific community. These roles range from becoming research advisors to graduate programs, to joining the ASCB Minorities Affairs Committee as regular and ad hoc members, to organizing scientific workshops at regional scientific meetings. Participants also report becoming more active in scholarly pursuits relating to their professional development. In posttraining surveys, 22 participants report attending scientific meetings and more than half of these report attending the annual ASCB meeting at least once every $2 \mathrm{yr}$. Twenty-one report being members of professional societies, with 17 being active members of ASCB.

Tenure and promotion among VP Program participants over the life of the program was examined, and the results are summarized in Figure 4 . Sixteen of the 32 faculty participants of the program through 2011 were tenure-eligible faculty members, and 14 of the 16 were awarded tenure following their VP experience. The majority of these advanced from the rank of assistant professor to associate professor and reported being tenured within 5 yr after their VP

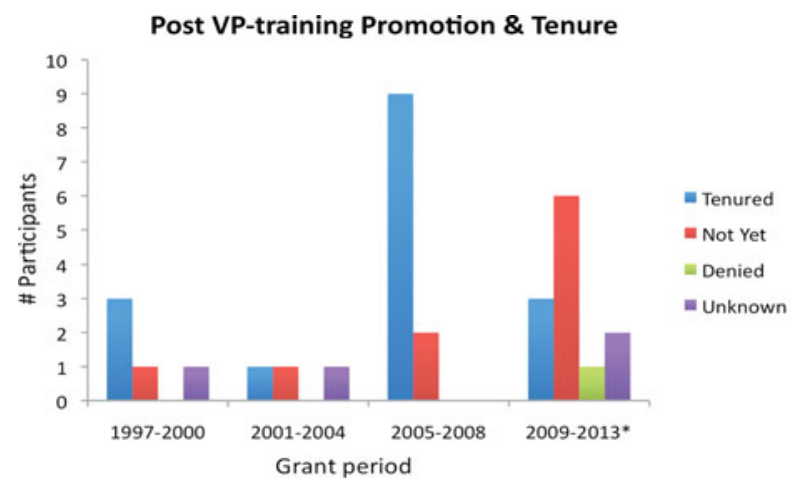

Figure 4. Academic promotion of past participants of the VP Program. Tenure-eligible faculty members who participated in the VP Program self-reported on their tenure status following completion of the program; self-reported are summarized here. The period listed corresponds to the training period of each participant. 
training. One past participant reported being denied tenure, while another nine reported that they had yet to come up for tenure or were not yet eligible for tenure review. A number of the past participants reported that their institution does not award tenure or that they are not in tenure-eligible positions. Only two participants were tenured prior to the start of their VP experience.

\section{DISCUSSION}

The most important outcome of the VP Program to date has been that it has achieved its originally intended goals of enhancing the professional accomplishments of faculty at MSIs by enhancing participant research skills and practices.

Since the program's inception, the number of participants has increased in each 4-yr period since 2001 (Figure 1), indicating both an interest and a need for the program. Analysis of the racial and ethnic composition of participants shows that African-American and Hispanic faculty members are the most represented among both the applicant and participant pools in all periods of analysis. The increase in the number of Hispanic participants is less consistent than noted for African Americans and may be the result of fewer HSIs contributing applicants. The absence of Native Americans from the population of program participants may reflect the lower numbers of Native American faculty members in the broader academic community. This suggests the need for the VP Program to reach out more broadly to this population, especially to faculty at tribal colleges. Since 2005, there has been an increase in the number of applications and participants to the program from non-URM faculty at MSIs. This observation reflects the need for professional development of non-URM faculty as well as URM faculty.

The numbers of pre- and post-VP publications produced by matched MSI faculty peers, as well as the numbers of pre-VPera publications by participants are similar (Table 1 ). This similarity may be the consequence of a "ceiling effect," imposed by high nonresearch demands on faculty members at their home institutions. Specifically, Visiting Professors come from teaching-intensive institutions with larger teaching responsibilities and fewer opportunities for research as compared with colleagues at research-intensive institutions. Many also lack full-time PhD trainees and research staff and depend on undergraduate and master's-level students to complete research projects. Accordingly, limited research time, material, and human resources place a ceiling on the number of publications each can generate.

We hypothesize that post-VP-era increases in publications by Visiting Professors reflect a higher level of self-efficacy following training and may have a basis in the contributions of senior faculty mentoring, research funding, and training environment. This is further strengthened by the observation that faculty members participating in the program more than once published the majority of manuscripts. It is interesting to note that the range of numbers (as indicated by the SDs) of publication by Visiting Professors showed little change following participation in the VP Program (Table 1). For the VP population in the post-VP era, in which the average publication output is doubled, the relatively unchanged SDs suggest that the effects of the program are similar among the participants.
Grant-funding successes by Visiting Professors correlated positively with VP training (Tables 1 and 2). Although MSI faculty peers were also successful in securing grants in both the pre-VP and post-VP era, there was an $\sim 50 \%$ decline in new grants received by this peer group in the post-VP era. The larger number of grants held by Visiting Professors in the post-VP era is likely a result of VP training, as many of the Visiting Professors report writing collaborative grants with their sponsors and often return to their home institutions energized to sustain their research practices. Many also are likely to have spent more time writing grants during the post-VP era than their peers, as they did not hold the level of funding held by their matched peers. The increase in the SD (from 0.24 in the pre-VP era to 1.38 in the post-VP era) for numbers of new grants secured by Visiting Professors indicates significant variation in productivity among the participants; this might be in part a discipline-specific effect, wherein the amount of funding available and opportunities for funding may not be equivalent in the fields in which Visiting Professors work.

There is a positive correlation between participation in the VP Program and subsequent grant funding. While the average grant size per Visiting Professor increased in the post-VP era, the average grant size for their matched peers decreased from the pre-VP era to the post-VP era. This change is not statistically significant. One peer scientist held an extremely large grant, and thus the mean difference between the two groups was not significant, despite Visiting Professors having a greater rate of funding. Because of the limitations in the survey data, we do not know the frequency with which each applied for funding, nor do we have a complete view of success rates on first submissions. Overall, the federal grantfunding success rates and average sizes of grants among MSI faculty are difficult to calculate, and it is therefore difficult to place the values presented above into a larger context.

Data presented show that participation in the VP Program correlates with other positive posttraining activities and practices. The VP Program participants reported engaging in activities that support their individual professional development and the development of their student trainees. Visiting Professors have also reported that they have been able to bring their experiences into their teaching classrooms. Although the extent to which individuals with bench research experience bring direct benefit to classroom teaching remains debatable (Smeby, 1998; Marsh and Hattie, 2002; Pocklinton and Tupper, 2002), their involvement in classroom biology education does support didactic and other teaching methods (Miller et al., 2008).

Finally, the majority of Visiting Professors eligible for tenure and promotion were tenured and promoted. We do not know the significance of this, due to the small number of candidates in this group and the absence of tenure and promotion information for their peers.

It is likely that the effectiveness of the VP Program is due in no small part to the program being one of a suite of opportunities offered to these scientists. Other highly structured, nonresearch opportunities offered by the MAC are among the important foundations and contributors to participant success. Seventeen of the past 32 Visiting Professors have participated in the MAC Linkage Fellows Program, which provides support for outreach activities in cell biology at participants' home institutions. Twelve past Visiting Professors 


\section{Linking Training Practices to Outcomes}

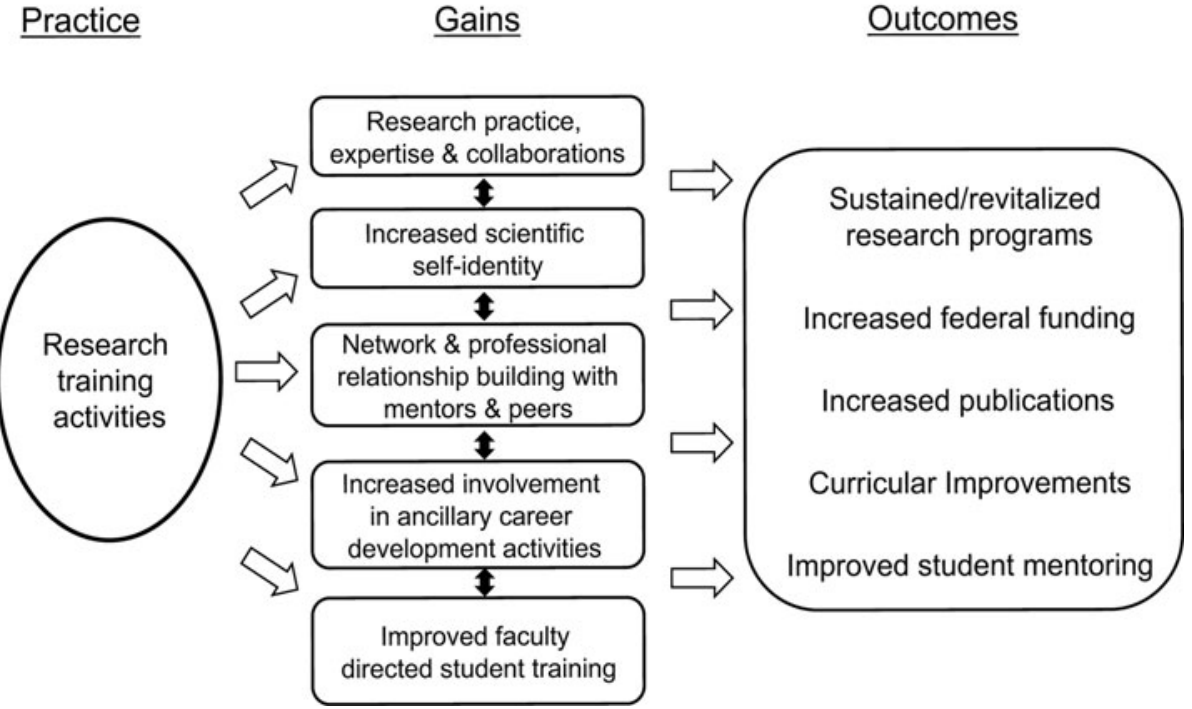

Figure 5. The working model for junior faculty career development includes practice, gains, and outcomes. The model highlights the expected gains of program participants en route to reaching the desired program outcomes, which contribute to career successes. "Gains" represent short-term VP Program-derived achievements and "Outcomes" represent long-term accomplishments of participants. Closed (black) arrows illustrate the strongest "nearest-neighbor" relationship between gains of participants in the program. have participated in the Junior Faculty and Postdoctoral Fellows Career Development Workshop, which provides career development training. In 2005, participation in this workshop became mandatory for all Visiting Professors. Visiting Professors are also required to present their work at the annual ASCB meeting. Together, these activities can reinforce the scientific identities of the participants by building selfefficacy and a sense of belonging to the scientific community (Estrada et al., 2011).

At the undergraduate level, there is strong evidence that authentic research experiences reinforce scientific identity and the pursuit of a career in science (e.g., Nagda et al., 1988; Hathaway et al., 2002; Russell et al., 2007; Thiry et al., 2011; Hernandez et al., 2012). Similarly, faculty development programs build the networks that support faculty academic success, and faculty lacking access to career development resources lack the foundations for professional success (Hitchcock et al., 1995; Morzinski and Fisher, 2002). The focus of the VP Program is to engage faculty at teaching-intensive institutions in research activity, thus re-establishing the framework for appropriate career development. Strengthening this framework-comprising skills such as motivation, persistence, mentoring - reinforces the scientific identity of the participating Visiting Professor. More important is the potential lasting and positive effect on the Visiting Professor's students.

The information gathered through the VP Program represents the initial step in longitudinal and retrospective studies that will be useful in defining challenges to individual scientific career development, especially for those from underrepresented groups and faculty at MSIs. Participation in the VP Program has been shown to lay the foundations for faculty members to achieve individual long-term career goals by increasing their engagement in research activities, which impact their teaching practices. Figure 5 presents a model that highlights the important gains linking mentored research practice to the desired outcomes for participants of the program. This model serves as a guide to assist faculty mentors and sponsors to strengthen the development and success of junior faculty. This is especially true at MSIs, where faculty plays an important role educating and preparing URM students for careers in STEM fields.

The disparity in research funding between majority and minority scientists (Ginther et al., 2011) was the focus of a recent report $(\mathrm{NIH}, 2012 \mathrm{a})$. In response to this report, the $\mathrm{NIH}$ has recently announced new initiatives, including a renewed emphasis on underresourced undergraduate institutions on the premise that these institutions can produce more students prepared for research careers (http:/ / commonfund .nih.gov/diversity/initiatives.aspx). A key element in the improved preparation of undergraduate students is the ability of the faculty to teach through inquiry and to provide students opportunities to engage in authentic research (Hernandez et al., 2012). The VP Program offers important insights that can inform the design of effective strategies to enhance the development of MSI faculty. Among the elements that are key to the success of the participants, we present three here: 1) a modest annual financial investment of $\sim \$ 6000$ per participant; 2) the commitment of host scientists; and 3) the willingness of the Visiting Professor's home institution to allow the faculty member to explore new ways to introduce inquiry-based learning into students' experiences. The patient, often person-by-person investment in faculty development promises to ultimately translate into educational gains that benefit the larger scientific community in terms of scientific productivity and workforce development.

\section{ACKNOWLEDGMENTS}

This work is supported by T36GM008622 from the National Institute of General Medical Science to the ASCB and R25GM083270 to A.G.C. Human subject data collection and the writing of the manuscript were supported by grant R25GM083270 to A.G.C. The authors thank ASCB Senior Manager Deborah McCall for administrative and technical support and information gathering. We also thank Joy Quill of 
C. J. Quill \& Associates, Inc., for data tracking and analysis and Allison Delong of the Brown University Center for Statistical Sciences for assistance with statistical analysis. We further acknowledge the commitment and contributions of current and former members of the MAC and the leadership of the ASCB.

\section{REFERENCES}

Boyack KW, Jordan P (2011). Metrics associated with NIH funding: a high-level view. J Am Med Inform Assoc 18, 423-431.

Burrelli J, Rapoport A (2008). Role of HBCUs as Baccalaureate-Origin Institutions of Black S\&E Doctorate Recipients, InfoBrief: NSF 08-319, Arlington, VA: National Science Foundation.

Drayton B, Falk J (2006). Dimensions that shape teacher-scientist collaborations for teacher enhancement. Sci Educ 90, 734-761.

Estrada M, Woodcock A, Hernandez PR, Schultz PW (2011). Toward a model of social influence that explains minority student integration into the scientific community. J Educ Psychol 203, 206-222.

Federation of American Societies for Experimental Biology (2013). Sequestration and Flat Funding for NIH Threaten Innovation and Progress. www.faseb.org/Portals/0/PDFs/opa/NIH $\% 20$ Sequestration \%20Flat\%20Funding\%20analysis.pdf (accessed 6 April 2013).

Feldman KA (1987). Research productivity and scholarly accomplishment of college teachers as related to their instructional effectiveness: a review and exploration. Res High Educ 26, 227-298.

Garde-Hansen J, Calvert B (2007). Developing a research culture in the undergraduate curriculum. Active Learn High Educ 8, 105-116.

Gasman M (2008). Minority-Serving Institutions: The Path to Successfully Educating Students of Color, Indianapolis, IN: Lumina Foundation for Education. www.luminafoundation.org/ publications/Minority_Serving_Institutions.pdf (accessed 11 July 2013).

Gasman M (2009). Minority-serving colleges deserve more respect. Chronicle of Higher Education. October 11, 2009. http://chronicle .com/article/Minority-Serving-Colleges-D/48726 (accessed 11 July 2013).

Ginther DK, Schaffer WT, Schnell J, Masimore B, Liu F, Haak LL, Kington R (2011). Race, ethnicity, and NIH research awards. Science 19, 1015-1019.

Hathaway RS, Nagda BA, Gregerman SR (2002). The relationship of undergraduate research participation to graduate and professional education pursuit: an empirical study. J Coll Stud Dev 43, 614-631.

Hernandez PR, Schultz PW, Estrada M, Woodcock A, Chance RC (2012). Sustaining optimal motivation: a longitudinal analysis of interventions to broaden participation of underrepresented students in STEM. J Educ Psychol 105, 89-107.

Hitchcock MA, Bland CJ, Hekelman FP, Blumenthal M (1995). Professional networks: the influence of colleagues on the academic success of faculty. Acad Med 70, 1108-1116.

Komaromy M, Grumbach K, Drake M, Vranizan K, Lurie N, Keane D, Bindman AB (1996). The role of black and Hispanic physicians in providing health care for underserved populations. N Engl J Med 334, 1305-1310.

Marsh H, Hattie J (2002). The relationship between research productivity and teaching effectiveness: complementary, antagonistic or independent constructs. J High Educ 73, 603-641.

Miller S, Pfund C, Pribbenow CM, Handelsman J (2008). Scientific teaching in practice. Science 332, 1329-1330.
Minstrell J, van Zee E (eds.) (2000). Inquiry into Inquiry Learning and Teaching in Science, Washington, DC: American Association for the Advancement of Science.

Morzinski JA, Fisher JC (2002). A nationwide study of the influence of faculty development programs on colleague relationships. Acad Med 77, 402-406.

Murray-García JL, García JA, Schembri ME, Guerra LM (2001). The service patterns of a racially, ethnically, and linguistically diverse housestaff. Acad Med 76, 1232-1240.

Nagda BA, Gregerman SR, Jonides J, von Hippel W, Lerner JS (1998). Undergraduate student-faculty research partnerships affect student retention. Rev High Educ 22, 55-72.

National Academy of Science (2011). Expanding Underrepresented Minority Participation: America's Science and Technology Talent at the Crossroads, Washington, DC: National Academies Press. www.nap.edu/catalog.php?record_id=12984 (accessed 11 July 2013).

National Institutes of Health (NIH) (2012a). Draft Report of the Advisory Committee to the Director Working Group on Diversity in the Biomedical Research Workforce. http://acd.od.nih.gov/ Diversity\%20in\%20the \%20Biomedical\%20Research\%20Workforce $\%$ 20Report.pdf (accessed 30 April 2013).

NIH (2012b). Research Grants, Research Project Grants: Average Size. http://report.nih.gov/nihdatabook/charts/Default.aspx? chartId=155\&catId $=2$ (accessed 11 July 2013).

National Science Foundation (2011). Women, Minorities, and Persons with Disabilities in Science and Engineering, Special Report NSF 11309, Arlington, VA. www.nsf.gov / statistics/wmpd (accessed 11 July 2013).

Pocklinton T, Tupper A (2002). No Place to Learn, Vancouver Canada: University of British Columbia Press.

President's Council of Advisors on Science and Technology (2012). Engage to Excel: Producing One Million Additional College Graduates with Degrees in Science, Technology, Engineering and Mathematics, Washington, DC: U.S. Government Office of Science and Technology. www.whitehouse.gov/administration/ eop/ostp/pcast/docsreports (accessed 1 May 2013).

Russell SH, Hancock MP, McCullough J (2007). Benefits of undergraduate research experiences. Science 316, 548-549.

Smeby J-C (1998). Knowledge production and knowledge transmission. The interaction between research and teaching. Teach High Educ 3, 5-20.

Spencer SJ, Steele CM, Quinn DM (1999). Stereotype threat and women's math performance. J Exper Social Psych 35, 428.

Steele CM (1997). A threat in the air: how stereotypes shape the intellectual identities and performance of women and African-Americans. Am Psychol 52, 613-629.

Summers M, Hrabowski F III (2006). Preparing minority scientists and engineers. Science 311, 1870-1871.

Thiry H, Laursen SL, Hunter A-B (2011). What experiences help students become scientists? A comparative study of research and other sources of personal and professional gains for STEM undergraduates. J High Educ 82, 357-388.

U.S. Department of Education (2008). Characteristics of MinorityServing Institutions and Minority Undergraduates Enrolled in These Institutions, Washington, DC: National Center for Education Statistics. nces.ed.gov / pubsearch / pubsinfo.asp?pubid $=2008156$ (accessed 11 July 2013). 